\title{
The American Association for Thoracic Surgery Ethics Forum: How should a surgeon respond to a patient's request to hasten death?
}

\author{
Kathleen N. Fenton, MD, ${ }^{a}$ and Grace B. Huffman, $\mathrm{MD}^{\mathrm{b}}$
}

\footnotetext{
From the ${ }^{a}$ William Novick Global Cardiac Alliance, Memphis, Tenn; and ${ }^{b}$ Winchester Medical Center Winchester, Va.

Received for publication Aug 8, 2018; revisions received Oct 4, 2018; accepted for publication Oct 12, 2018; available ahead of print Nov 27, 2018.

Address for reprints: Kathleen N. Fenton, MD, William Novick Global Cardiac Alliance, 1750 Madison Ave, Suite 500, Memphis, TN 38104 (E-mail: KathleennF@ gmail.com).

J Thorac Cardiovasc Surg 2019;157:1943-7

$0022-5223 / \$ 36.00$

Copyright (C) 2018 Published by Elsevier Inc. on behalf of The American Association for Thoracic Surgery https://doi.org/10.1016/j.jtcvs.2018.10.078
}

\section{"You are not to be indifferent to the sufferings of others, but it is meant to affect you deeply."}

As cardiothoracic surgeons, we generally think of ourselves as healers, whose role is to restore our patients' health. Yet, some patients' problems have no medical solutions. These patients may express to us a readiness, willingness, or even desire to die, and may ask us to not delay their deaths or even to help them to die more quickly.

Vignette: JT, age 76 years, is a widower seen 6 weeks after reoperative multivessel coronary bypass. Although he is recovering appropriately, he reports that he remains sore and tired, and admits that he still misses his wife. "Doc," he asks, "can't you just give me something to help me end this? I've had a good life but I'm ready to go."

In addressing an ethical question, one often begins at an emotional or intuitive level: Physicians want to help suffering patients. This emotional response impels us to act. Moral reflection means pausing to look as if from an outsider's perspective and study the reasons behind our decisions. ${ }^{2}$ This understanding may help us defend our intuition or, perhaps, realize that another course of action might be better.

Our first appeal to moral reasoning is on the prescriptive level: What does the law allow? What has been done in this situation in the past - are there precedents? Is there a usual course of action, one guided by policy?

\section{LEGAL BACKGROUND}

Patients approaching the end of life are often asked what is most important to them: Do they want to live as long as possible or else as comfortably as possible? These differences in treatment goals are reflected in the law: The right to refuse unwanted treatment is long-standing, and in the early 1970s, the Quinlan case ${ }^{3}$ established the legal right for patients to discontinue life-sustaining medical interventions. Likewise, the law allows use of pain medications and

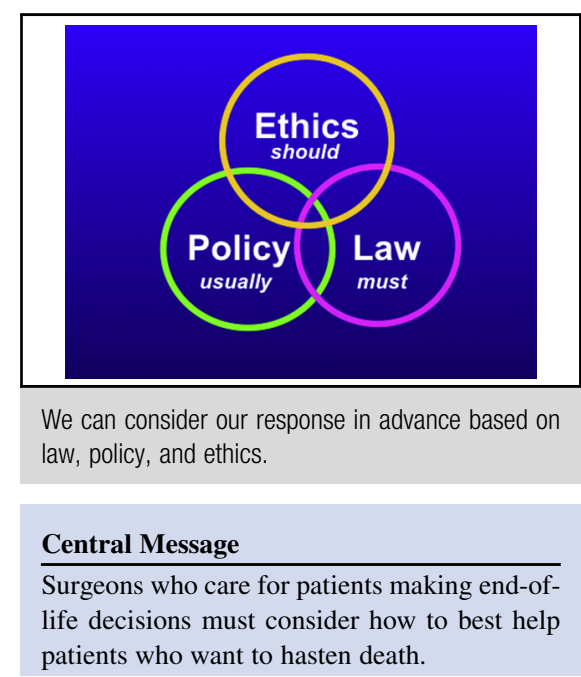

palliative sedation to relieve symptoms, even if it is possible that death could be hastened. ${ }^{4}$ Active euthanasia (Table 1) is illegal throughout the United States, but physician-assisted suicide (PAS) is now legal in a growing number of states. ${ }^{5}$ The term PAS has been determined to "describe the practice with the greatest precision" and to distinguish it from "euthanasia." Other terms, such as "aid in dying" or "death with dignity" were deemed in a recent American Medical Association report as unacceptably ambiguous. ${ }^{6}$

\section{ETHICAL BACKGROUND}

There is broad support among both bioethicists and the lay public for the right to withhold or withdraw unwanted treatment, but substantial discord remains concerning PAS and euthanasia. The ethical background and related disputes have been extensively discussed and argued in the medical and philosophical literatures. Our summary of the main points of these considerations includes ample citations from those literatures, which the reader can consult for more details and nuanced arguments. Disagreements include whether there is an ethical difference between not prolonging death and hastening it, and whether a physician's role could include participation in the latter. Although there is no evidence that medications used appropriately to relieve symptoms at the end of life actually hasten death, the use of pain medication or sedation that is directed toward relief of symptoms is both legal and ethical. $^{4}$ 
TABLE 1. Brief summary of interventions at the end of life

\begin{tabular}{|c|c|c|c|}
\hline Intervention & Intention of intervention & Cause of death & Example \\
\hline Palliative care & $\begin{array}{l}\text { Relief of intolerable } \\
\text { symptoms }\end{array}$ & Underlying disease & $\begin{array}{l}\text { A patient with stage IV lung cancer has severe pain } \\
\text { from metastatic lesions. Escalating doses of } \\
\text { morphine are prescribed to relieve pain. The small } \\
\text { possibility that respiratory depression could result } \\
\text { and might hasten death is accepted, but the desired } \\
\text { effect is pain relief, not death ("double effect"). }\end{array}$ \\
\hline $\begin{array}{l}\text { Physician-assisted } \\
\text { suicide }\end{array}$ & Death & $\begin{array}{l}\text { Medication prescribed } \\
\text { by a physician that is } \\
\text { administered by the patient }\end{array}$ & $\begin{array}{l}\text { A patient with esophageal cancer is given a } \\
\text { prescription for a large dose of a barbiturate, which } \\
\text { she self-administers at home after saying goodbye } \\
\text { to her family. }\end{array}$ \\
\hline Euthanasia & Death & $\begin{array}{l}\text { Medication prescribed and } \\
\text { administered by a } \\
\text { physician }\end{array}$ & $\begin{array}{l}\text { After valve replacement, a patient sustains a large } \\
\text { hemorrhagic stroke. He is unable to feed or care } \\
\text { for himself. At his request, his physician } \\
\text { administers a fatal intravenous dose of fentanyl. }\end{array}$ \\
\hline
\end{tabular}

*Adapted from.

What about when death is the intended effect? Both PAS and voluntary euthanasia involve a patient's autonomous decision to hasten death (Table 1) and are distinct from palliative care. ${ }^{7}$ Individual physicians whose patients desire to hasten death may or may not consider the distinction between PAS and euthanasia to be morally relevant to their own decisions about whether or not to participate, but should recognize the similarities. Different ethical systems can be used to help the practicing physician reflect on how to field requests for PAS or euthanasia from patients (Table 2).

\section{Ethical Arguments in Favor of Physician-Assisted Suicide and Euthanasia}

Although perhaps the most common reason given in support of legalizing PAS and euthanasia-that we "should" help patients who are suffering -is an emotional or intuitive response rather than a morally reflective one, it is presented as (and may legitimately be) a "should" or "ought to" reason. In our strong medical subculture, though, problems that are not necessarily "medical" are given "medical" solutions ${ }^{9}$; thus, we may be unknowingly biased to seek medical resolutions to problems that may have cultural, psychosocial, or spiritual explanations and solutions. In fact, the majority of patients seeking to actively end their lives, in most studies, do so for reasons other than physical suffering. ${ }^{10-12}$

A principlist's support for PAS and euthanasia emphasizes autonomy: Following on the broad agreement that the patient has a right to decline unwanted treatment, he argues that the patient must be permitted to determine the manner and timing of her own death, because she alone can know her own suffering. The principle of justice may then be invoked to defend legalizing voluntary euthanasia. To allow PAS without allowing (voluntary) euthanasia is seen as discrimination, ${ }^{10}$ because patients who want to die but who are physically unable to self-administer medications will not be able to exercise this "right." The principlist may also contend that prohibiting euthanasia limits autonomy by "forcing" patients to choose PAS out of fear that progression of disease may render them physically incapable of self-administering the drugs.

Consequentialist reasoning takes a different approach: Society allows both withdrawal and refusal of treatment, so it should not oppose PAS or euthanasia, because the outcome is the same. ${ }^{13}$ In addition, consequentialists argue

TABLE 2. Brief summary of ethical system approaches*

\begin{tabular}{|c|c|}
\hline System & $\begin{array}{c}\text { Viewpoint from which ethical issues are } \\
\text { decided }\end{array}$ \\
\hline Principlist & $\begin{array}{l}\text { Weigh principles of autonomy (the patient } \\
\text { has a right to determine a course of action), } \\
\text { beneficence (act in the patient's best } \\
\text { interest), nonmaleficence (avoid doing } \\
\text { harm), and justice (treat patients fairly) }\end{array}$ \\
\hline $\begin{array}{l}\text { Utilitarian/ } \\
\text { consequentialist }\end{array}$ & $\begin{array}{l}\text { Determine morality of an action based on its } \\
\text { outcome or expected outcome: A good } \\
\text { action is one that results in the greatest } \\
\text { amount of "pleasure" or the least amount } \\
\text { of suffering. }\end{array}$ \\
\hline Deontologic & $\begin{array}{l}\text { Emphasize duty of an action: A good action is } \\
\text { one that fulfills the person's duty. }\end{array}$ \\
\hline Virtue ethics & $\begin{array}{l}\text { Emphasize the effect on the person acting: A } \\
\text { good action is one that makes a person } \\
\text { good (virtuous). }\end{array}$ \\
\hline \multicolumn{2}{|c|}{$\begin{array}{l}\text { *Readers interested in more detailed information may want to consult the following: } \\
\text { Principlist ethics. In: Beauchamp T, Childress J, eds. Principles of Biomedical Ethics. } \\
\text { 6th ed. New York: Oxford University Press; 2008. Consequentialist ethics. Stanford } \\
\text { Encyclopedia of Philosophy. Available at: https://plato.stanford.edu/entries/conse } \\
\text { quentialism/. Deontologic ethics. Stanford Encyclopedia of Philosophy. Available at: } \\
\text { https://plato.stanford.edu/entries/ethics-deontological/. Virtue ethics. Stanford Encyclo- } \\
\text { pedia of Philosophy. Available at: https://plato.stanford.edu/entries/ethics-virtue/. }\end{array}$} \\
\hline
\end{tabular}


that PAS and euthanasia will happen whether legal or not, and, in fact, already occur, ${ }^{14}$ so it seems logical to legalize them to regulate them and provide safeguards for involved parties. $^{15}$

\section{Ethical Arguments Against Physician-Assisted Suicide and Euthanasia}

The same principlist approach that emphasizes autonomy in favoring PAS and euthanasia may also be used to argue against them. In considering whether or not a physician should help her patient end his life, a principlist who emphasizes nonmaleficence (rather than autonomy) concludes that a physician should not harm her patient, nor help him to harm himself, because causing death is harmful. ${ }^{16}$

Likewise, consequentialist reasoning can also be used in a broader way to argue that society's use of resources to legalize and regulate PAS and euthanasia diverts those resources from what is truly needed: access to good palliative care (including hospice). ${ }^{10}$ Hospice and palliative care physicians overwhelmingly oppose PAS and euthanasia, ${ }^{17}$ knowing that good palliation of symptoms can reduce or nearly eliminate a patient's desire for hastening death. (Their true wish is typically to avoid living with suffering, not to avoid living.) The resource reallocation argument, though, seems a relatively weak one given the enormous size of healthcare expenditures as a whole. The "slippery slope" argument used by some opponents of PAS (that allowing it will lead to permitting voluntary euthanasia, which will ultimately result in involuntary euthanasia $^{10,11,13}$ ) is also, at its base, a consequentialist argument.

The strongest ethical arguments opposing PAS and euthanasia come from deontology and virtue ethics. Both of these approaches emphasize the traditional role of physician as healer and reliever of symptoms, but in most cases exclude what they refer to as "killing" the patient. Deontologists argue that the duty of physicians is to heal their patients or, when this is not possible, to relieve their suffering and accompany them with care and affection, but not to help them hasten their deaths. ${ }^{11,16,18}$ In virtue ethics, morally good actions are those that, when performed repeatedly, lead to growth in virtue of the actor. Good actions are then those that make us "good" physicians. Modifications of either ethical approach could, of course, allow for PAS or euthanasia under a larger umbrella of compassion, but would require changing the concept of the physician's role. More commonly, ethicists using deontology or virtue ethics argue that even if society chooses to allow patients to end their lives, it is not the role of physicians to help them do so. ${ }^{16,19}$ Some, in fact, have argued formation of a new specialty to assist patients requesting death. ${ }^{20}$

Other objections to PAS and euthanasia come from reflecting on our cultural past and our concerns about the future. The desire to end one's life has traditionally been considered a manifestation of psychologic illness, and for much of history, suicide was illegal and suicide attempts were even punishable by law. Although in patients with terminal illness, most physicians appreciate the desire to avoid prolonged suffering, in practice it can be difficult to exclude external factors (eg, depression, polypharmacy, social and financial concerns, and other issues) that may be contributing to the request to hasten death. Some disability rights activists have also expressed concern that prohibiting suicide by the general "healthy" public, but permitting it for the infirm or those with disabilities, implies that somehow their lives are less valuable and therefore represents another form of discrimination. ${ }^{11}$

Looking toward the future potential consequences of legal PAS, some fear that ultimately the right to die will evolve into a duty to die, motivated by the patient's desire to save her family from additional emotional burden or financial loss; some patients may even want to spare society as a whole from the perceived burden of their care. ${ }^{11}$

Finally, many cultural and religious traditions express opposition to PAS and euthanasia based on their perception of the value of human life and the meaning of suffering. The Islamic Code of Medical Ethics ${ }^{21}$ states: "Mercy killing like suicide finds no support except in the atheistic way of thinking that believes that our life on this earth is followed by void. If this is sound thinking, it would have been reasonable for almost all of the human race to commit suicide and get rid of the difficulties of life for indeed hardly a life is devoid of difficulty or pain." This sentiment is echoed, with variations, in Christian, Jewish, and Buddhist traditions, as well as in many native religions and cultures.

\section{CONTROVERSIES REGARDING THE DETAILS}

Besides the question of whether a physician can ethically hasten a patient's death, various other matters relate to details of regulating PAS. Existing laws differ greatly in terms of these details, and there are major disagreements even among strong proponents of its legalization. For example, should only patients with terminal illness be allowed to request PAS? A terminal diagnosis is not a requirement in The Netherlands, but in Washington, only patients with less than 6 months to live may be permitted PAS. Those who favor limiting PAS to those with terminal illness argue, essentially from a utilitarian perspective, that these patients are going to die soon anyway, so the consequences of their decision to end their lives sooner are not as grave as would be the case for a patient without terminal illness. Another controversy involves whether or not the patient should be required to have some type of intractable "suffering"; this is one of the criteria in The Netherlands, but not in Washington.

Other details of the laws that are contentious include whether or not a waiting period should be required, whether or not notification of family members should be required or recommended, and whether to insist that the prescription be 
provided by a specific category of physician, such as one with special training in this area, or one who has known the patient for an extended period of time.

Controversies also exist regarding the scope of the laws. Should a mature minor be allowed to make this serious and irreversible decision, and if so, under what conditions? In places where euthanasia is allowed, can it be used to relieve the suffering of infants and children, or of other patients who lack (and possibly have never had) a decisionmaking capacity? Should laws require mental illness to be excluded (or, if present, treated) before providing the prescription, and if so, how? Should patients be allowed to request PAS if their suffering is primarily due to mental illness?

Consideration of these controversies is not a trivial matter. Moral reflection, at a personal level and at a societal level, should lead us to address all of these questions before agreeing that it is a good idea to actively end a patient's life, because the very fact that these uncertainties exist indicates that we have not yet settled the ethical dilemma at its depth.

\section{HOW CAN WE (ALL) HELP OUR PATIENTS?}

In the short term, it is unlikely that broad consensus will be reached regarding how we should respond to a patient's request to hasten death. However, we can agree on many issues to better help patients whose illness cannot be cured, so that they experience minimal suffering and have a "good death.'”

First, we should have conversations about end-of-life issues with our patients and their families early and often, and in language that is very clear. ${ }^{22}$ We must know our patients well to understand their values and help them make ethical decisions. A clinician who is unable-through lack of training, time, or inclination-to lead these discussions should refer the patient to a palliative care specialist for ongoing dialogue about goals of care and advance care planning. We should also avoid encouraging "aggressive" treatment as soon as it becomes apparent that such treatment is futile or inconsistent with the patient's goals of care. These 2 steps can reduce a patient's later frustration and resultant sense that he needs to hasten his own death or the physician's impression that he can somehow absolve his previous actions in having provided interventions that may have been unwarranted or unwanted. Furthermore, both as physicians and as citizens, we need to advocate publicly for good palliative and hospice care, which are poorly understood, even among many physicians. Solutions to the logistic and financial problems that result from prolonged illness must also be encouraged. Finally, we should make sure that all of our patients are treated in a dignified manner. "Death with dignity" should never be synonymous with taking one's own life.

Vignette: JT must be reassured that because he is still recovering from surgery, some discomfort and fatigue are not unusual. Good pain control should be ensured and emotional support provided. Referral to palliative care and for formal evaluation/treatment for depression may be appropriate.

It is important to use ethical principles to determine our role as physicians and to guide our patients to make decisions that accord with their own values. After careful evaluation of the available evidence and analysis of the patient's situation within a medical ethics framework, it should be easier to provide resources for patients to relieve their suffering and help them have the best death possible.

\section{Conflict of Interest Statement}

Authors have nothing to disclose with regard to commercial support.

The authors thank Dr Martin McKneally for help with the preparation of the Ethics Forum presentation and for the original version of the Central Image, Dr Robert Sade for reviewing this article, and the American Association for Thoracic Surgery and Society of Thoracic Surgeons Joint Ethics Forum for granting Dr Fenton the scholarship to study at Alden March Bioethics Institute.

\section{References}

1. Blessed Mother Teresa. The Compassion That Cures, One Heart Full of Love. Cincinnati: Franciscan Media; 1988.

2. Larmore C. Reflection and morality. Soc Philos Policy. 2010;27:1-28.

3. Supreme Court of New Jersey 355 A.2d 647 (N.J. 1976). In Re: Quinlan. Menikoff I, ed. Law and Bioethics. Washington: Georgetown University Press; 2001:242-252.

4. Kamdar MM, Doyle KP, Sequist LV, Rinehart TJ, Maytal G, Flores EJ, et al. Massachusetts general hospital. Case 17-2015. A 44-year-old woman with intractable pain due to metastatic lung cancer. $N$ Engl J Med. 2015;372:2137-47.

5. State-by-State guide to physician-assisted suicide. Available at: https:// euthanasia.procon.org/view.resource.php?resourceID $=000132$. Accessed July 16,2018 .

6. American Medical Association Council on Ethical and Judicial Affairs. Report 5A-18. Available at: https://www.ama-assn.org/sites/default/files/media-browser/ public/.../a18-ceja5.pdf. Accessed November 15, 2018.

7. American Medical Association Code of Ethics. Available at: https://www.amaassn.org/sites/default/files/media-browser/code-of-medical-ethics-chapter-5. pdf. Accessed November 15, 2018.

8. Beauchamp T, Childress J. Principles of Biomedical Ethics. 6th ed. New York: Oxford University Press; 2008.

9. Brannigan MC. Cultural Fault Lines in Healthcare: Reflections on Cultural Competency. Lanham, MD: Lexington Books, Rowman \& Littlefield Publishing; 2012.

10. Arras JD. On the slippery slope in the empire state: the New York state task force on physician-assisted death. In: DeGrazia D, Mappes TA, Brand-Ballard J, eds. Biomedical Ethics. 7th ed. New York: McGraw-Hill; 2011:432-8.

11. Anderson RT. Always care, never kill: how physician-assisted suicide endangers the weak, corrupts medicine, compromises the family, and violates human dignity and equality. Backgrounder. 2015;3004.

12. Stevens KR Jr. Emotional and psychological effects of physician-assisted suicide and euthanasia on participating physicians. Linacre Q. 2006;73:203-16.

13. Rachels J. Active and passive euthanasia. In: DeGrazia D, Mappes TA, BrandBallard J, eds. Biomedical Ethics. 7th ed. New York: McGraw-Hill; 2011:395-9.

14. Kon A. Neonatal euthanasia is unsupportable: the Groningen protocol should be abandoned. Theor Med Bioeth. 2007;28:453-63.

15. Miller FG, Quill TE, Brody H, Fletcher JC, Goston LO, Meier DE. Regulating physician-assisted death. In: DeGrazia D, Mappes TA, Brand-Ballard J, eds. Biomedical Ethics. 7th ed. New York: McGraw-Hill; 2011:426-32.

16. Boudreau JD, Somerville MA. Euthanasia is not medical treatment. Br Med Bull. 2013;106:45-66. 
17. Sheahan L. Exploring the interface between 'physician-assisted death' and palliative care: cross-sectional data from Australasian palliative care specialists. Intern Med J. 2016;46:443-51.

18. Callahan D. Killing and allowing to die. In: DeGrazia D, Mappes TA, BrandBallard J, eds. Biomedical Ethics. 7th ed. New York: McGraw-Hill; 2011:399-402. 19. Paris J. Why involve physicians in assisted suicide. Am J Bioeth. 2009;9:32-4.
20. Sade RM, Marshall MF. Legistrothanatry: a new specialty for assisting in death Perspect Biol Med. 1996;39:222-4.

21. Islamic Organization for Medical Sciences. Islamic Code of medical ethics International Conference on "Islamic Code for Medical and Health Ethics", December 2004, Cairo, Egypt.

22. Berry SR. Just say die. J Clin Oncol. 2008;26:157-8. 